\title{
Biocomputational Screening and Pharmacological Studies of Gymnema sylvester in Contrast to Human CCR5 and CXCR4 Chemokine Receptors
}

\author{
Kavitapu VV ${ }^{1}$ and Sharma $\mathrm{S}^{2 *}$ \\ ${ }^{1}$ School of Biosciences and Technology, Vellore Institute \\ of Technology, Tamil Nadu, India \\ ${ }^{2}$ Department of Bioinformatics, BioNome Pvt. Ltd., \\ Bangalore, India \\ *Corresponding author: Sameer Sharma, Department \\ of Bioinformatics, BioNome Pvt. Ltd., Bangalore, India
}

Received: July 10, 2021; Accepted: J uly 28, 2021;

Published: August 04, 2021

\begin{abstract}
Viral diseases have remained a major global threat regardless of significant advances in therapeutic and treatment strategies. The advancement of viral resistance to drugs, along with several side effects, has resulted in critical medical issues, especially when administered in combination for extended treatment periods. Natural product-based therapies for the health of humans are associated with lower toxicity and fewer side effects. Virtual in-silico screening has been shown to be effective in addressing the unique challenges of antiviral drug development, making the process quicker, safer and less expensive. Novel ligands are evolving as potential agents, which are efficient in blocking virus-cell fusion to surpass the main disadvantages of traditional Highly Active Antiretroviral (HAART) drugs used in HIV-1 infection. The plant Gymnema sylvestre contains various bioactive compounds with medicinal properties. The HIV entry process can be blocked during the binding activity of glycoprotein gp120 viral envelope to one of the two receptors CXCR4 or CCR5 and binding to both the CD4 receptors. The significance of chemokine receptors as an antiHIV target depends on the fact that they are involved in the entry of the virus into the cell at the early stages. Thus, the HIV/coreceptor relationship has emerged as a key focus for developing new antiviral strategies for the prevention and also treatment of HIV infection. In the present study, the phytochemicals selected from Gymnema sylvestre were subjected to ADME analysis. This was followed by the molecular docking analysis and MD simulation to estimate the selected ligands drug likeness, which may serve as new leads for the cure of HIV-1 infections.
\end{abstract}

Keywords: Gymnema sylvestre; Molecular docking; Anti-HIV-1; CCR5; CXCR4

\section{Introduction}

Despite considerable advances in human medicine over the past few years, viral infections remain a major global concern. Viral infections can cause not only fatal acute clinical complications like influenza, dengue fever, but also leads to chronic diseases such as HIV, Hepatitis $C$ that need long-term treatment and hence result in high health-care costs. The capability for any of these viral infections to spread to pandemic levels, in particular, is a striking concern these days, and one such condition is HIV-1 infection.

\section{Epidemiology and etiology}

Human Immunodeficiency Virus (HIV) which can cause Acquired Immunodeficiency Syndrome (AIDS), is a critical health concern affecting an overall 37 million individuals [1] and further more people are infected by this disease worldwide [2]. Clinically, this virus was identified first in The United States in the year 1981 and consequently there was a gradual surge in the infection rate across the world. People of all genders, races and countries can be infected by the virus. About 39 million deaths were reported globally in individuals affected by HIV-1 since the start of the epidemic. The virus has most predominance in sub-Saharan Africa, with approximately $68 \%$ of HIV infected individuals and in The UK, this infection was reported to be around 103,600 living individuals. Besides Africa, the impact of this infection along with AIDS was also observed in Eastern Europe, America and in South and Central Asia significantly.

Centers for Disease Control and Prevention (CDC) estimated that around $95 \%$ of HIV infected individuals do not contribute to the transmission of the virus to others. Over the past few years, there is a decline in deaths globally due to advanced treatment methods, but the condition remains same in few poor resource countries as they have less access to new drug therapies. The highly active antiretroviral therapy (HAART), which employs a combination of medications targeting viral proteins such as reverse transcriptase, integrase, and protease, is currently the most helpful therapy for HIV-1 infected patients. This caused a drastic decline in the deaths of AIDS patients, but the use of these drugs for prolonged treatment periods causes intolerable side effects.

\section{Pathophysiology}

When specific bodily fluids make contact with any of the injured tissue, mucous membrane, or the blood circulation, it may lead to the HIV transmission. It is mainly categorized into two major types, which are HIV-1 and HIV-2. According to previous studies, HIV-1 causes more severe infection and the disease worsens in untreated
Austin J Proteomics Bioinform \& Genomics - Volume 6 Issue 1 - 2021 ISSN : 2471-0423 | www.austinpublishing group.com

Sharma et al. (c) All rights are reserved
Citation: Kavitapu VV and Sharma S. Biocomputational Screening and Pharmacological Studies of Gymnema sylvester in Contrast to Human CCR5 and CXCR4 Chemokine Receptors. Austin J Proteomics Bioinform \& Genomics. 2021; 6(1): 1029. 
patients when compared to HIV-2. HIV-1 infection is depicted by the permissive CD4+ $\mathrm{T}$ lymphocytes loss, subsequently resulting in the development of cancers defining AIDS and opportunistic infections [3]. The association of the HIV-1 glycoprotein gp120 with the cellular receptor $\mathrm{CD} 4$ is an essential primary step in the viral entry. A conformational change is induced in the gp120 during the viral entry into host cells and facilitates the further interaction with either of the two co-receptors, chemokine receptor 5 (CCR5) or CXC-Chemokine Receptor 4 (CXCR4) [4].

\section{Human CXCR4 \& CCR5}

In the human genome, there are two main clusters of C-C chemokine genes [5] and two clusters of C-X-C genes, as well as various non-clustered or mini-cluster genes of both forms. C-X-C Chemokine Receptor Type 4 (CXCR4) is a rhodopsin-like GPCR with 352-amino acids, 3 extracellular loops, extracellular N-terminal domain, 3 intracellular loops, an intracellular C-terminal domain, and 7 transmembrane helices. CXCR4 might exist as a monomer or dimer, nanocluster or as a higher-order oligomer, in the plasma membrane. It is one of many chemokine co-receptors from which HIV can infect CD4+ T lymphocytes and thus play a crucial role in the HIV life cycle infecting the host cell. It is the most commonly expressed chemokine receptor and is active in a variety of pathological and physiological conditions [6].

C-C Chemokine Receptor Type 5 (CCR5) is a 7-transmembrane $\mathrm{G}$ protein-coupled receptor that controls the trafficking and effector roles of macrophages, immature dendritic cells and memory or effector T-cells [7]. In addition, CCR5 is the key receptor in the entrance of HIV type 1 and type 2 virus into the host cell [8]. It was identified as an essential co-receptor for the entry of HIV strains of macrophage tropic type [9]. The chemokine receptor CCR5 has a molecular weight of $40.6 \mathrm{kDa}$ and is made up of 352 amino acids. Chemokine receptor CCR 5 when activated by a ligand, it releases the ai and $\beta \gamma$ G-protein subunits [10]. The regulation of CCR5 expression is dependent on a few criteria such as factors involved in activation, signaling and transporting of the receptor, genetically related factors, and environmental factors or other stimulants.

The virus preferentially uses CCR5 during the initial stages of infection, while the alternative co-receptor CXCR4 is utilized in the later stage of HIV infection, as the infected person is advancing towards development of AIDS. Thus, they are considered a crucial part of the HIV-1 life cycle. CCR5 and CXCR4 chemokine receptors are related structurally [11] and are generally found on the host immune cells surface [12]. By preventing this association, it could be possible to address the clinical limitations of currently available Highly Active Anti-Retroviral Drug Therapies (HAARTs). Chemokines have increased in importance in recent years since it was evident that they play important role in a variety of disease mechanisms [13], which are autoimmune disease, infectious diseases like HIV or AIDS, inflammation and, recently, cancer [14]. Based on their critical function, agents aimed at CXCR4 expression down-regulation may have a few advantages for HIV-infected patients.

\section{Gymnema sylvestre}

Gymnema sylvestre is a therapeutically important plant that contains substantial biologically important phytochemicals [15]. Gymnema sylvestre belongs to the family of Apocynaceae that grows in many parts of Africa, Asia and Australia. It is an endangered species that grows slowly, and is a perennial medicinal woody climber located in central and peninsular India [16]. Gymnema sylvestre is familiarly known as Gurmar [17], which translates to "sugar destroyer". Because of the occurrence of phytocompounds such as gymnemic acid, gurmarin and gymnemasaponins, G. sylvestre was considered one of the crucial botanicals believed to exhibit blood glucose lowering capacity [18]. As a result, it is commonly used in Western and ayurvedic systems of medicine, and it is also listed as an anti-diabetic herb in the Indian Pharmacopoeia.

Gymnema sylvestre has a variety of secondary metabolites. Oleanane saponins and dammarane saponins [19] are examples of such metabolites. It mainly constitutes Gymnemagenin, Catechol, Gymnemagenol, Tetradecanoic acid, Gymnemanol, Cedrene $V_{6}$, Squalene, Stigmasterol, Nerolidol, Beta amyrin, 1-Docosene, Lupeol, Gymnemasaponin II, Gymnemic acid I, Gymnemic acid II, Gymnemic acid III, Isophytol and Gymnemic acid IV. Gymnema sylvestre has a vast history of its use in natural or herbal remedies all over the world, and its leaf extract is well known for its antiviral, antibiotic, anti-inflammatory, anti-oxidant, lipid-lowering activities, anticancer, gastro and hepatoprotective. It is also used to treat inflammations, eye problems, diabetes, snakebites, and family planning.

Additionally, it also has sweet suppression [20], antihypercholesterolemic, hepatoprotective and antimicrobial properties [21]. Further, various portions of the herb, such as the leaves, roots, and stem, have been made use in traditional medicine schemes as diuretic, cardiotonic, laxative, digestive, uterine tonic and stimulant [22]. Despite the fact that this plant has been known to be valuable due to its various therapeutic properties, only a few studies were done, particularly clinical studies, on it.

\section{Materials and Methods}

\section{Target selection and prediction}

PubChem database (https://pubchem.ncbi.nlm.nih.gov) and PDB (www.rcsb.org/pdb) were used for retrieving the structures of the respective human protein receptors CXCR4 and CCR5 [23]. Furthermore, the criteria for the target structure were investigated using Protein Data Bank analysis and BLAST (https://blast.ncbi.nlm. nih.gov). Since the three-dimensional structure of the target proteins was not available in the PDB, the protein sequences of CXCR4 and CCR5 were obtained from the NCBI databases for the purpose of structure prediction. Furthermore, the targeting of the templates was performed using a homology search through NCBI and PubChem databases. Above $90 \%$ of homology for the selected template with respect to CXCR4 and CCR5 was observed in the terms of percent identification. Homology modelling was done using the tool SWISSMODEL (http://swissmodel.expasy.org). Thus, the structures obtained were visualized using PyMOL software [24].

\section{Protein and ligand preparation}

Using Discovery Studio Visualizer, the ions, ligands and water molecules were removed from the protein molecules [25]. This was followed by the addition of the polar hydrogen atoms to the target proteins. A total of 18 ligands were selected for the present study from the plant G. sylvestre. For all the selected ligands, Structure Data Format (SDF) files were downloaded using the PubChem 
database [26]. These were analysed using Marvin view, which is an advanced chemical visualizer for $2 \mathrm{D}$ or $3 \mathrm{D}$ structures of chemicals and their related information. The canonical SMILES IDs of all the selected ligands were noted and estimation of the physico-chemical properties [27] of these ligands was done using PubChem database. Following this, using Open Babel software, all the selected ligands were converted into 3D structure for the further use.

\section{Active binding site analysis}

The molecular docking process generally starts with determination of the active binding site of the selected proteins [28], which indicates the particular proteins restricted region [29]. Recognition of active binding sites was done using Biovia Discovery Studio 2021 Client. In this study Blind Docking, method was performed between two target proteins and all the selected ligands.

\section{Virtual screening of ligands}

Screening of ligands was done using PyRx software (https://pyrx. sourceforge.io/) which is an open-access and user-friendly tool. The binding affinities of all the ligands for both proteins were estimated [30] initially. The ligands, which exhibit high binding affinities, were subjected to the pharmacological analysis. The energy minimization of all the ligands was performed followed by conversion of .sdf file to .pdbqt file as this software works based on .pdbqt format and based on the minimum binding affinities ligands were screened further.

\section{Drug likeness analysis}

The analysis of drug-likeness was done to determine the presence of any cytotoxicity. All the selected ligands were estimated for their drug-like characteristics using Lipinski's rule of five [31]. This analysis was done using SwissADME (http://www.swissadme.ch/) database. The ligands that obey all the Lipinski's rule were further chosen for the docking analysis.

\section{ADMET prediction}

ADME stands for absorption, distribution, metabolism, excretion and toxicity in pharmacokinetics and pharmacology that describes the pharmaceutical compound disposition in an organism [32]. The SwissADME database that assembles data on properties associated with ADMET was used in the current study for the ADMET analysis.

\section{BOILED egg plot}

BOILED-Egg is an abbreviation of Brain or Intestinal Estimated permeation method. It is regarded as a precise model that calculates the tiny molecules polarity by effective functioning and BOILEDEgg is an accurate method of graphical classification. This plot was obtained after the input and processing of all ligands and was viewed in the SwissADME result page [33]. It provides the estimation of two primary parameters of ADME, i.e., Blood Brain Barrier (BBB) permeation and human passive gastrointestinal absorption (HIA) in the form of BOILED-Egg plot.

\section{Molecular docking using autodock vina}

The screened ligands were selected for the molecular docking analysis. Docking was performed using AutoDock Vina that is included in the PyRx software. The docking was done between the 2 target proteins (CXCR4 \& CCR5) and 17 screened ligands individually. Both the ligands and the selected target protein were converted to .pdbqt format initially. The grid box in the Vina search space was set for the maximum region for the docking process as the Blind Docking method was selected for the current study. This was followed by executing the AutoDock Vina and the docked structures were saved for further analysis.

\section{Structure visualization through biovia discovery studio 2021 client}

Biovia Discovery Studio was used for the visualization and analysis of docked ligand with the purified protein molecules [34]. The interaction with the docked ligand and protein can be visualized along with the possibility of adjustments in the ligand interactions. Besides this, receptor-ligand interactions on the $2 \mathrm{D}$ diagram can also be observed using this tool.

\section{Molecular Dynamics (MD) simulation}

Through the molecular docking, it was analysed that gymnemic acid III and gymnemic acid IV were exhibiting high binding affinities with both the target proteins. Hence, these two ligands were selected for the MD simulation to evaluate the relative stability of these ligands with respect to the target proteins CXCR4 and CCR5 [35]. The iMOD server (http://imods.chaconlab.org/) was used for performing the molecular dynamic's simulation. Based on the structural interaction of protein-protein type, the analysis of internal coordinates was done by this server. The analysis of stability, B-factor along with the molecular mobility, variance and eigenvalue calculation were also done using the iMODS.

\section{Results}

\section{Homology modelling of CXCR4 and CCR5}

The homology modelling of the target proteins was done using the tool SWISS-MODEL and were visualized through PyMOL software (Figure 1 and 2).

\section{Ligands (Table 1 and Figure 3) \\ Active binding site analysis}

The recognition of active binding site was determined using the Biovia Discovery Studio and the red spherical zone indicates the binding region of each target protein respectively (Figure 4 and 5) (Table 2).

\section{Drug likeness analysis}

Through the Lipinski filter analysis (Table 3) it was observed that

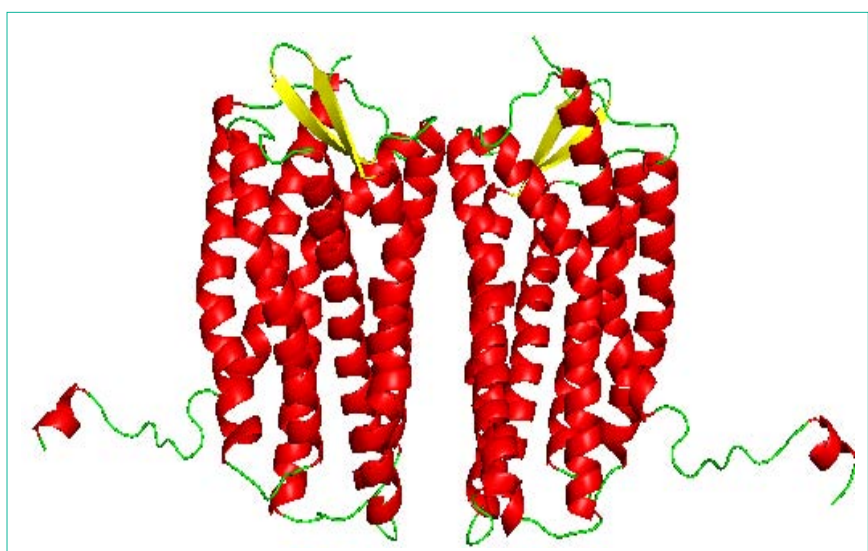

Figure 1: 3D structure of CXCR4 protein. 


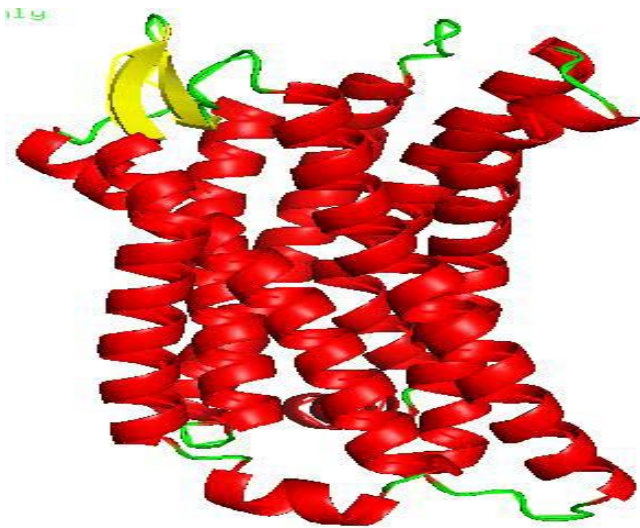

Figure 2: 3D structure of CCR5 protein

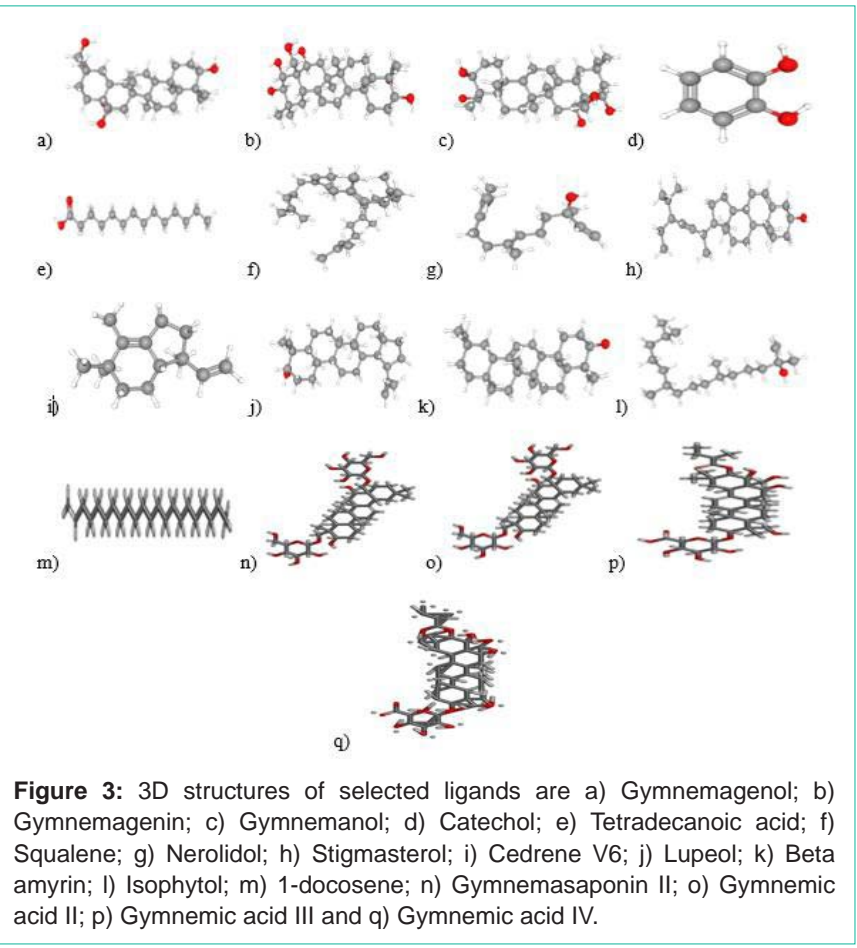

all the selected phytochemicals are in accordance with the Lipinski's rule and are proceeded with further analysis.

\section{ADMET prediction (Table 4) \\ BOILED egg plot}

The BOILED Egg model obtained shows high GI absorption for the molecules Gymnemagenol, Gymnemagenin, Gymnemanol, catechol, Tetradecanoic acid and Nerolidol (Figure 6).

\section{Molecular docking and structure visualization}

Through molecular docking, all the phytochemicals exposed high binding affinity (Table 4) or binding energies in contrast to CCR5 and CXCR4. Among the selected phytochemicals, gymnemic acid III and gymnemic acid IV have exhibited the highest binding affinity $(-15.4 \mathrm{Kcal} / \mathrm{mol}$ and $-15.7 \mathrm{Kcal} / \mathrm{mol})$ towards the target proteins and also showed significant hydrogen bonding and Vander Waal forces on the contrary to chemokine receptors (Figure 7 and 8 ).

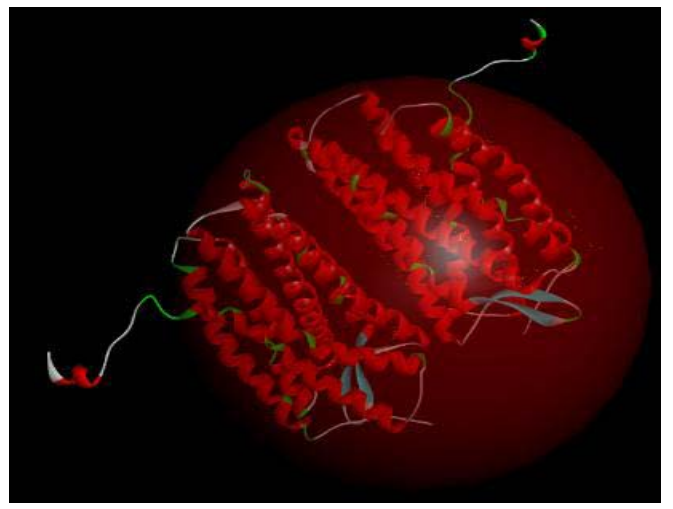

Figure 4: Active binding site of CXCR4 protein.

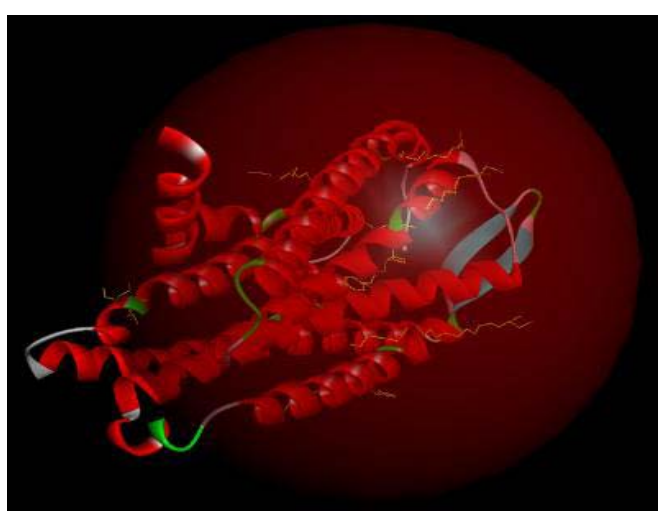

Figure 5: Active binding site of CCR5 protein.

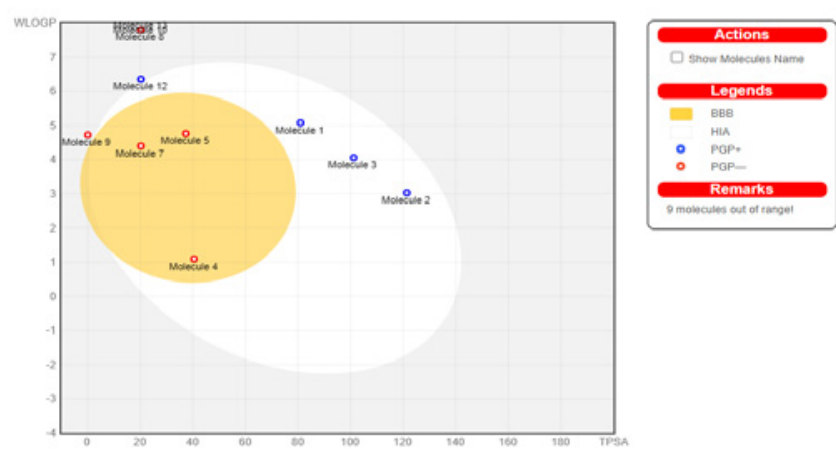

Figure 6: The yolk region reveals the physico-chemical space for highest probability of molecules for brain penetration whereas; the white region shows highly probable molecules being used by the GI. The outer grey space represents molecules with expected poor absorption by $\mathrm{Gl}$ tract and reduced brain penetration.

\section{Molecular Dynamics (MD) simulation}

In this study, iModS server was used for the molecular dynamic's simulation and results were obtained with an ID: 0301132717957 (Figure 9). The main-chain deformability is a measure of the capability of a given molecule to deform at each of its residues. The generated Eigenvalue was 2.63096e-05. The eigenvalue associated to each normal mode represents the motion stiffness and its value is associated with the energy required to deform the structure. The lower the eigenvalue, the easier the deformation. The variance factor 
Table 1: Physico-chemical properties of the ligands.

\begin{tabular}{|c|c|c|c|c|c|}
\hline Ligands & Molecular Formula & Molecular Weight & Monoisotropic Mass & Heavy Atom Count & TPSA \\
\hline Gymnemagenol & $\mathrm{C}_{30} \mathrm{H}_{50} \mathrm{O}_{4}$ & $474.7 \mathrm{~g} / \mathrm{mol}$ & $474.37091 \mathrm{~g} / \mathrm{mol}$ & 34 & $80.9 \AA^{2}$ \\
\hline Gymnemagenin & $\mathrm{C}_{30} \mathrm{H}_{50} \mathrm{O}_{6}$ & $506.7 \mathrm{~g} / \mathrm{mol}$ & $506.360739 \mathrm{~g} / \mathrm{mol}$ & 36 & $121 \AA^{2}$ \\
\hline Gymnemanol & $\mathrm{C}_{30} \mathrm{H}_{50} \mathrm{O}_{5}$ & $490.7 \mathrm{~g} / \mathrm{mol}$ & $490.365825 \mathrm{~g} / \mathrm{mol}$ & 35 & $101 \AA^{2}$ \\
\hline Catechol & $\mathrm{C}_{6} \mathrm{H}_{6} \mathrm{O}_{2}$ & $110.11 \mathrm{~g} / \mathrm{mol}$ & $110.036779 \mathrm{~g} / \mathrm{mol}$ & 8 & $40.5 \AA^{2}$ \\
\hline Tetradecanoic acid & $\mathrm{C}_{14} \mathrm{H}_{28} \mathrm{O}_{2}$ & $228.37 \mathrm{~g} / \mathrm{mol}$ & $228.20893 \mathrm{~g} / \mathrm{mol}$ & 16 & $37.3 \AA^{2}$ \\
\hline Squalene & $\mathrm{C}_{30} \mathrm{H}_{50}$ & $410.7 \mathrm{~g} / \mathrm{mol}$ & $410.391252 \mathrm{~g} / \mathrm{mol}$ & 30 & $0 \AA^{2}$ \\
\hline Nerolidol & $\mathrm{C}_{15} \mathrm{H}_{26} \mathrm{O}$ & $222.37 \mathrm{~g} / \mathrm{mol}$ & $222.198365 \mathrm{~g} / \mathrm{mol}$ & 16 & $20.2 \AA^{2}$ \\
\hline Stigmasterol & $\mathrm{C}_{29} \mathrm{H}_{48} \mathrm{O}$ & $412.7 \mathrm{~g} / \mathrm{mol}$ & $412.370516 \mathrm{~g} / \mathrm{mol}$ & 30 & $20.2 \AA^{2}$ \\
\hline Cedrene $\mathrm{V}_{6}$ & $\mathrm{C}_{15} \mathrm{H}_{24}$ & $204.35 \mathrm{~g} / \mathrm{mol}$ & $204.187801 \mathrm{~g} / \mathrm{mol}$ & 15 & $0 \AA^{2}$ \\
\hline Lupeol & $\mathrm{C}_{30} \mathrm{H}_{50} \mathrm{O}$ & $426.7 \mathrm{~g} / \mathrm{mol}$ & $426.386166 \mathrm{~g} / \mathrm{mol}$ & 31 & $20.2 \AA^{2}$ \\
\hline 1-Docosene & $\mathrm{C}_{22} \mathrm{H}_{44}$ & $308.6 \mathrm{~g} / \mathrm{mol}$ & $308.344301 \mathrm{~g} / \mathrm{mol}$ & 22 & $0 \AA^{2}$ \\
\hline Isophytol & $\mathrm{C}_{20} \mathrm{H}_{40} \mathrm{O}$ & $296.5 \mathrm{~g} / \mathrm{mol}$ & $296.307916 \mathrm{~g} / \mathrm{mol}$ & 21 & $20.2 \AA^{2}$ \\
\hline Gymnemasaponin II & $\mathrm{C}_{42} \mathrm{H}_{70} \mathrm{O}_{14}$ & $799 \mathrm{~g} / \mathrm{mol}$ & $798.476557 \mathrm{~g} / \mathrm{mol}$ & 56 & $239 \AA^{2}$ \\
\hline Gymnemic acid II & $\mathrm{C}_{43} \mathrm{H}_{68} \mathrm{O}_{14}$ & $809 \mathrm{~g} / \mathrm{mol}$ & $808.460907 \mathrm{~g} / \mathrm{mol}$ & 57 & $230 \AA^{2}$ \\
\hline Gymnemic acid III & $\mathrm{C}_{41} \mathrm{H}_{66} \mathrm{O}_{13}$ & $767 \mathrm{~g} / \mathrm{mol}$ & $766.450342 \mathrm{~g} / \mathrm{mol}$ & 54 & $224 \AA^{2}$ \\
\hline Gymnemic acid IV & $\mathrm{C}_{41} \mathrm{H}_{64} \mathrm{O}_{13}$ & $764.9 \mathrm{~g} / \mathrm{mol}$ & $764.434692 \mathrm{~g} / \mathrm{mol}$ & 54 & $224 \AA^{2}$ \\
\hline
\end{tabular}

Table 2: Binding affinity of selected phytochemicals for CXCR4 and CCR5 proteins.

\begin{tabular}{|c|c|c|}
\hline Phytochemicals & Binding affinity (Kcal/mol) for CXCR4 & Binding affinity (Kcal/mol) for CCR5 \\
\hline Gymnemagenol & -8.4 & -9.3 \\
\hline Gymnemagenin & -9.1 & -8.2 \\
\hline Gymnemanol & -8.4 & -8.9 \\
\hline Catechol & -5.2 & -5.5 \\
\hline Tetradecanoic acid & -5.2 & -6.1 \\
\hline Squalene & -7.4 & -8.5 \\
\hline Nerolidol & -6.6 & -6.3 \\
\hline Stigmasterol & -9.7 & -9.8 \\
\hline Cedrene $\mathrm{V}_{6}$ & -7.7 & -7.6 \\
\hline Lupeol & -8.9 & -10.3 \\
\hline 1-Docosene & -6.2 & -5.9 \\
\hline Isophytol & -6.3 & -7 \\
\hline Gymnemasaponin II & -9.3 & -10.6 \\
\hline Gymnemic acid II & -9.2 & -9.3 \\
\hline Gymnemic acid III & -15.4 & -15.7 \\
\hline Gymnemic acid IV & -15.2 & -15.7 \\
\hline
\end{tabular}

is inversely proportional to the eigenvalue. In the elastic network model, each dot denotes one spring within the respective atoms pair and the dots are coloured according to the stiffness (Figure 10).

\section{Discussion}

The possible and most reliable method for identification of antiviral properties of the desirable compounds is through the methods of chemoinformatic methods or using in-silico screening. Various in-silico and in-vitro research have reported the potential use of phytochemicals for the viral infection treatment [36]. Using protein- ligand docking computational techniques, this research presents findings that identify updated molecular criteria and determinants for effectual binding of small-molecule ligands to human CCR5 and CXCR4 chemokine receptors, the primary biological targets for HIV entry blockers [37].

Through pharmacological analysis and results from the molecular docking, have shown that all the phytochemicals determined high binding affinity in contrast to CCR5 and CXCR4. This study has shown that among the selected phytochemicals, gymnemic acid III 
Table 3: Lipinski filter analysis.

\begin{tabular}{|c|c|c|c|c|c|}
\hline Ligands & Molecular formula & Hydrogen Bond Acceptor & Hydrogen Bond Donor & cLogP & Molar Refractivity \\
\hline Gymnemagenol & $\mathrm{C}_{30} \mathrm{H}_{50} \mathrm{O}_{4}$ & 4 & 4 & 4.73 & 138.37 \\
\hline Gymnemagenin & $\mathrm{C}_{30} \mathrm{H}_{50} \mathrm{O}_{6}$ & 6 & 6 & 3.17 & 140.69 \\
\hline Gymnemanol & $\mathrm{C}_{30} \mathrm{H}_{50} \mathrm{O}_{5}$ & 5 & 5 & 4 & 139.53 \\
\hline Catechol & $\mathrm{C}_{6} \mathrm{H}_{6} \mathrm{O}_{2}$ & 2 & 2 & 0.97 & 30.49 \\
\hline Tetradecanoic acid & $\mathrm{C}_{14} \mathrm{H}_{28} \mathrm{O}_{2}$ & 2 & 1 & 4.45 & 71.18 \\
\hline Squalene & $\mathrm{C}_{30} \mathrm{H}_{50}$ & 0 & 0 & 9.38 & 143.48 \\
\hline Nerolidol & $\mathrm{C}_{15} \mathrm{H}_{26} \mathrm{O}$ & 1 & 1 & 4.19 & 74 \\
\hline Stigmasterol & $\mathrm{C}_{29} \mathrm{H}_{48} \mathrm{O}$ & 1 & 1 & 6.96 & 132.75 \\
\hline Cedrene $\mathrm{V}_{6}$ & $\mathrm{C}_{15} \mathrm{H}_{24}$ & 0 & 0 & 4.38 & 68.52 \\
\hline Lupeol & $\mathrm{C}_{30} \mathrm{H}_{50} \mathrm{O}$ & 1 & 1 & 7.31 & 135.14 \\
\hline 1-Docosene & $\mathrm{C}_{22} \mathrm{H}_{44}$ & 0 & 0 & 8.67 & 107.39 \\
\hline Beta amyrin & $\mathrm{C}_{30} \mathrm{H}_{50} \mathrm{O}$ & 1 & 1 & 7.18 & 134.88 \\
\hline Isophytol & $\mathrm{C}_{20} \mathrm{H}_{40} \mathrm{O}$ & 1 & 1 & 6.18 & 98.98 \\
\hline Gymnemasaponin II & $\mathrm{C}_{42} \mathrm{H}_{70} \mathrm{O}_{14}$ & 14 & 10 & 0.93 & 203.13 \\
\hline Gymnemic acid II & $\mathrm{C}_{43} \mathrm{H}_{68} \mathrm{O}_{14}$ & 7 & 14 & 2.97 & 207.58 \\
\hline Gymnemic acid III & $\mathrm{C}_{41} \mathrm{H}_{66} \mathrm{O}_{13}$ & 8 & 13 & 2.64 & 197.84 \\
\hline Gymnemic acid IV & $\mathrm{C}_{41} \mathrm{H}_{64} \mathrm{O}_{13}$ & 8 & 13 & 2.55 & 197.37 \\
\hline
\end{tabular}

Table 4: Admesar analysis.

\begin{tabular}{|c|c|c|c|c|}
\hline Ligands & Blood brain barrier & GI absorption & $\begin{array}{c}\text { Permeability glycoprotein } \\
\text { Substrate }\end{array}$ & $\begin{array}{c}\text { Log S (scale Insoluble }<-10<\text { Poorly }<-6< \\
\text { Moderately }<-4<\text { Soluble }<-2 \text { Very }<0<\text { Highly) [Water } \\
\text { solubility] }\end{array}$ \\
\hline Gymnemagenol & No & High & Yes & -5.20 (Moderately soluble) \\
\hline Gymnemagenin & No & High & Yes & -3.55 (Soluble) \\
\hline Gymnemanol & No & High & Yes & -4.37 (Moderately soluble) \\
\hline Catechol & Yes & High & No & -1.18 (Soluble) \\
\hline Tetradecanoic acid & Yes & High & No & -4.51 (Moderately soluble) \\
\hline Squalene & No & Low & No & -7.48 (Poorly soluble) \\
\hline Nerolidol & Yes & High & No & -3.15 (Soluble) \\
\hline Stigmasterol & No & Low & No & -5.47 (Moderately soluble) \\
\hline Cedrene $\mathrm{V}_{6}$ & No & Low & No & -4.09 (Moderately soluble) \\
\hline Lupeol & No & Low & No & -6.74 (Poorly soluble) \\
\hline 1-Docosene & No & Low & Yes & -8.39 (Poorly soluble) \\
\hline Beta amyrin & No & Low & Yes & -7.16 (Poorly soluble) \\
\hline Isophytol & No & Low & Yes & -5.5 (Moderately soluble) \\
\hline Gymnemasaponin II & No & Low & Yes & -1.54 (Soluble) \\
\hline Gymnemic acid II & No & Low & Yes & -3.21 (Soluble) \\
\hline Gymnemic acid III & No & Low & Yes & -2.62 (Soluble) \\
\hline Gymnemic acid IV & No & Low & Yes & -2.26 (Soluble) \\
\hline
\end{tabular}

and gymnemic acid IV have exhibited a momentous binding affinity and relative stability towards the chemokine receptors through molecular docking and molecular dynamic simulation. This implies that the phytocompounds from the plant G. sylvestre can be used as novel leads for the HIV-1 treatment and can be further investigated through in vivo studies for their antiviral potential.

Among the various research studies, which have surprising aspects, the current study assures that the selected phytochemicals from the plant G. sylvestre act as anti-HIV agents with respect to the human CCR5 and CXCR4 that are chosen as the target proteins. For the faster drug development and advancements, systematic analysis has shown that in-silico strategies for the discovery of new drugs is more successful and quicker when compared to other methods on the basis of biological reports. This novel strategy has also the potential to save time and resources in comparison to other techniques. From the above observations, the phytochemicals of plant Gymnema 


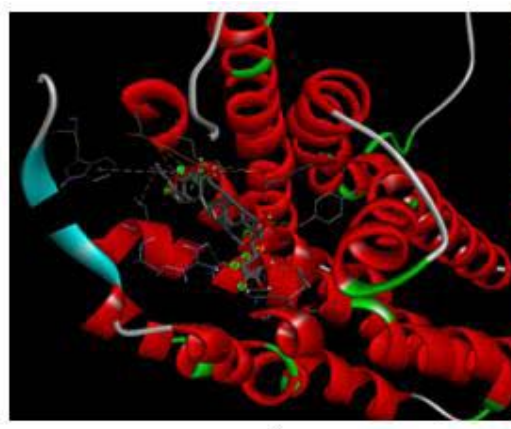

a)

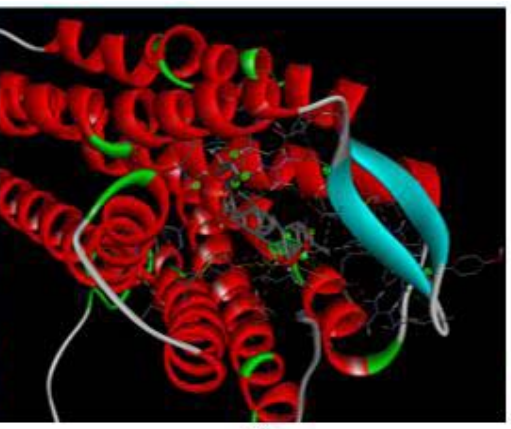

b)

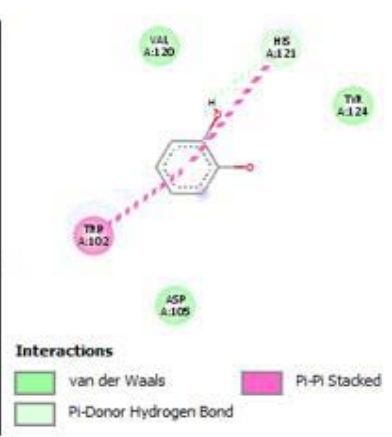

c)

Figure 7: a) \& b) Docked gymnemic acid III and docked gymnemic acid IV with CCR4 protein; c) 2D diagram of receptor-ligand interactions of docked catechol with CCR4 protein.

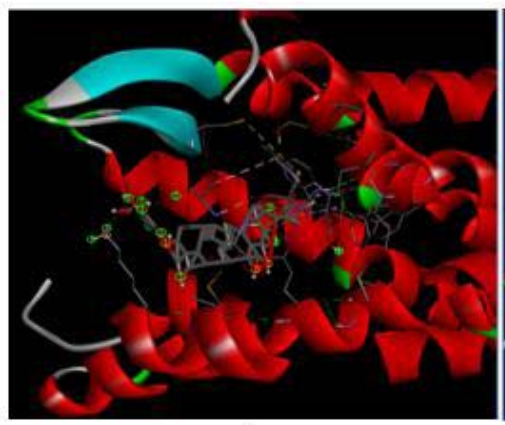

a)

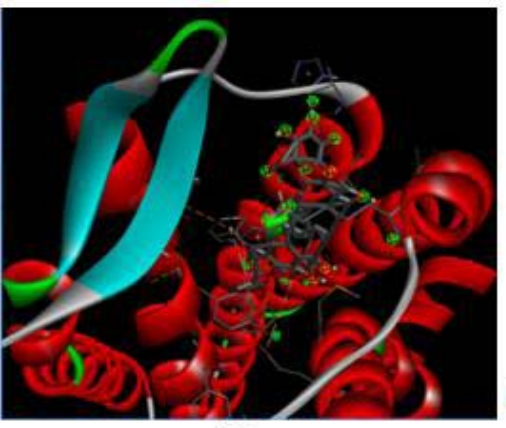

b)

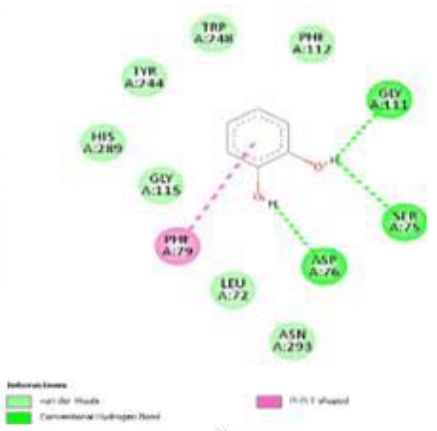

c)

Figure 8: a) \& b) Docked Gymnemic acid III and docked Gymnemic acid IV with CCR5 protein; c) 2D diagram of receptor-ligand interactions of docked Catechol with CCR5 protein.

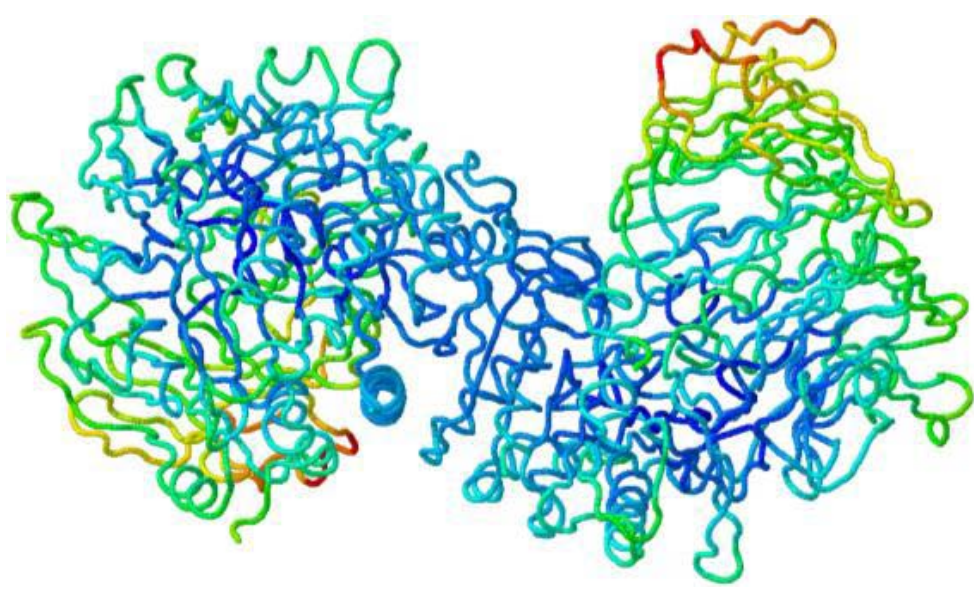

Figure 9: Normal Mode Analysis (NMA) mobility.

sylvestre, especially Gymnemic acid III and Gymnemic acid IV can be considered as potential agents in the novel anti-viral drug development for HIV-1 and other related viruses.

\section{Conclusion}

This research work was performed to identify and analyses the human chemokine receptors CCR5 and CXCR4 in contrast to phytochemicals present in Gymnema sylvestre through molecular docking mechanism. Various types of phytochemicals present in the G. sylvestre are beneficial in numerous harmful diseases as well as blood-related disorders. According to the results of the molecular docking and pharmacological analysis, it was found that all the phytochemicals that were taken for this research work are beneficiary in the treatment and act as potential targets for the human chemokine receptors CXCR4 and CCR5. In terms of pharmacological analysis, all the phytochemicals (Gymnemagenin, Catechol, 

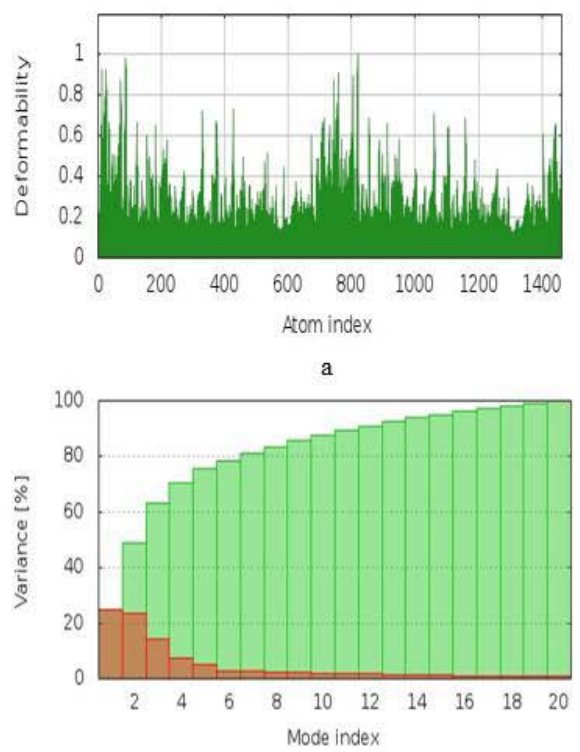

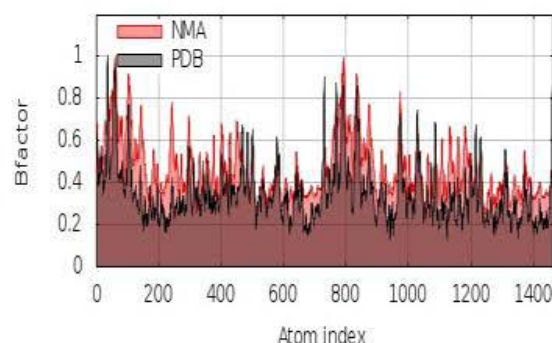

b

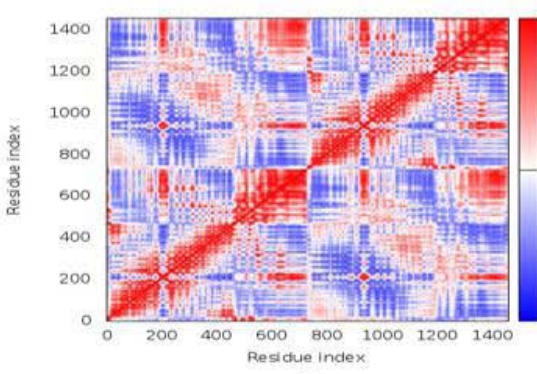

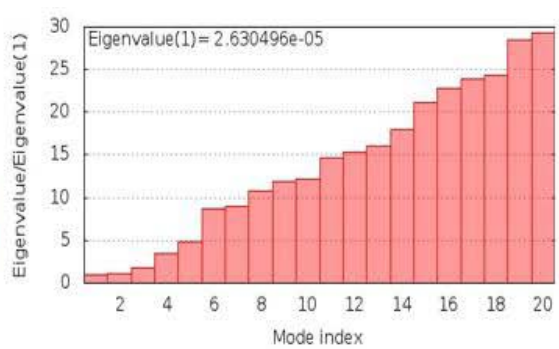

c

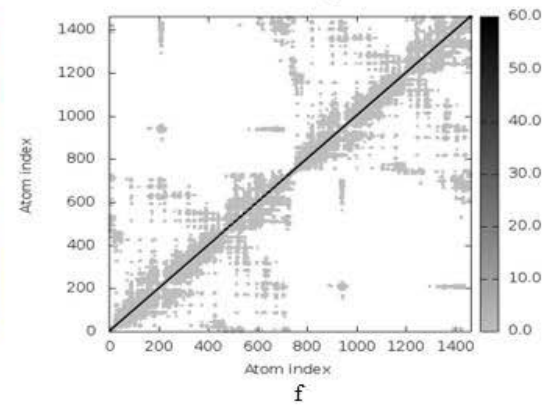

Figure 10: Results of MD simulation. a) Deformability; b) B-factor; c) eigenvalue; d) variance (individual (red) and cumulative (green) variances); e) Covariance map (correlated (red), uncorrelated (white) or anti-correlated (blue) motions of coupled residues) and f) elastic network (dark grey dots indicate the stiffer springs and vice versa)

Gymnemagenol, Tetradecanoic acid, Gymnemanol, Cedrene $\mathrm{V}_{6}$, Squalene, Stigmasterol, Nerolidol, Beta amyrin, 1-Docosene, Lupeol, Gymnemasaponin II, Gymnemic acid I, Gymnemic acid II, Gymnemic acid III and Isophytol) were screened through SWISSADME server.

These phytochemicals have passed the entire standard or the drug development parameters for the further process such as Blood Brain Barrier, Gastro-intestinal absorption, glycoprotein, cLogP, and Lead likeness. In case of molecular docking, all the phytochemicals exposed high binding affinity or binding energy in contrast to the human chemokine receptors CCR5 and CXCR4. Among the selected phytochemicals, gymnemic acid III and gymnemic acid IV have exhibited a considerable binding affinity towards the chemokine receptors and showed significant hydrogen bonding and Vander Waal forces in contrary to the chemokine receptors.

Based on the results of pharmacological analysis and molecular dynamic simulation, it was analysed that gymnemic acid III and gymnemic acid IV have significant stability followed by the momentous interaction with respect to the human CCR5 and CXCR4 chemokine receptors. Hence, it has been identified and predicted that all compounds, especially gymnemic acid III and gymnemic acid IV may possibly serve as new leads for the cure of HIV-1 infections, and these results might be used in the future for in vivo studies to test their effects on the cure of HIV-1 infections.

\section{References}

1. Wilkins Tom. "HIV 1: epidemiology, pathophysiology and transmission". Nursing Times. 2020; 116: 40-42.

2. Carrieri A, Pérez-Nueno VI, Fano A, Pistone C, Ritchie DW \& Teixidó J. Biological Profiling of Anti-HIV Agents and Insight into CCR5 Antagonist Binding Using in silico Techniques. Chem Med Chem: Chemistry Enabling Drug Discovery. 2009; 4: 1153-1163.

3. Gorry PR \& Ancuta P. Coreceptors and HIV-1 pathogenesis. Current HIVI
AIDS Reports. 2011; 8: 45-53.

4. Mirza MU, Saadabadi A, Vanmeert M, Salo-Ahen OM, Abdullah I, Claes S, et al. Discovery of HIV entry inhibitors via a hybrid CXCR4 and CCR5 receptor pharmacophore-based virtual screening approach. European Journal of Pharmaceutical Sciences. 2020; 155: 105537.

5. Samson M, Labbe O, Mollereau C, Vassart G \& Parmentier M. Molecular cloning and functional expression of a new human CC-chemokine receptor gene. Biochemistry. 1996; 35: 3362-3367.

6. Doranz BJ, Grovit-Ferbas K, Sharron MP, Mao SH, Goetz MB, Daar ES, et al. A small-molecule inhibitor directed against the chemokine receptor CXCR4 prevents its use as an HIV-1 coreceptor. The Journal of experimental medicine. 1997; 186: 1395-1400.

7. Blanpain C, Migeotte I, Lee B, Vakili J, Doranz BJ, Govaerts C, et al. CCR5 binds multiple CC-chemokines: MCP-3 acts as a natural antagonist. Blood, the Journal of the American Society of Hematology. 1999; 94: 1899-1905.

8. Oppermann M. Chemokine receptor CCR5: insights into structure, function, and regulation. Cellular signaling. 2004; 16: 1201-1210.

9. Mueller A \& Strange PG. The chemokine receptor, CCR5. The international journal of biochemistry \& cell biology. 2004; 36: 35-38.

10. Barmania F \& Pepper MS. CC chemokine receptor type five (CCR5): an emerging target for the control of HIV infection. Applied \& translational genomics. 2013; 2: 3-16.

11. Alkhatib G. The biology of CCR5 and CXCR4. Current Opinion in HIV and AIDS. 2009; 4: 96.

12. Murphy PM. Viral exploitation and subversion of the immune system through chemokine mimicry. Nature immunology. 2001; 2: 116-122.

13. Bonecchi R, Galliera E, Borroni EM, Corsi MM, Locati M \& Mantovani A. Chemokines and chemokine receptors: an overview. Front Biosci. 2009; 14: 540-551.

14. Zlotnik A, Yoshie O \& Nomiyama $\mathrm{H}$. The chemokine and chemokine receptor superfamilies and their molecular evolution. Genome biology. 2006; 7: 1-11.

15. Arunachalam KD, Arun LB, Annamalai SK \& Arunachalam AM. Potential anticancer properties of bioactive compounds of Gymnema sylvestre and its biofunctionalized silver nanoparticles. International Journal of Nanomedicine. 
2015; 10: 31.

16. Kanetkar P, Singhal R \& Kamat M. Gymnema sylvestre: a memoir. Journal of clinical biochemistry and nutrition. 2007; 41: 77-81.

17. Tiwari Pragya, Mishra BN, Sangwan Neelam S. Phytochemical and Pharmacological Properties of Gymnema sylvestre: An Important Medicinal Plant. BioMed Research International. 2014: 1-18.

18. Al-Romaiyan A, King AJ, Persaud SJ \& Jones PM. A novel extract of Gymnema sylvestre improves glucose tolerance in vivo and stimulates insulin secretion and synthesis in vitro. Phytotherapy Research. 2013; 27 : 1006-1011.

19. Devasagayam TPA. Recent Advances in Indian Herbal Drug Research Guest Editor: Thomas Paul Asir Devasagayam Introduction to Serial Reviews: Recent Advances in Indian Herbal Drug Research. Journal of Clinical Biochemistry and Nutrition. 2007; 40: 73

20. Khan F, Sarker M, Rahman M, Ming LC, Mohamed IN, Zhao C, et al Comprehensive review on phytochemicals, pharmacological and clinical potentials of Gymnema sylvestre. Frontiers in pharmacology. 2019; 10: 1223.

21. Arora DS \& Sood H. In vitro antimicrobial potential of extracts and phytoconstituents from Gymnema sylvestre R. Br. leaves and their biosafety evaluation. AMB Express. 2017; 7: 1-13.

22. Bishayee A \& Chatterjee M. Hypolipidaemic and antiatherosclerotic effects of oral Gymnema sylvestre R. Br. Leaf extract in albino rats fed on a high fat diet. Phytotherapy Research. 1994; 8: 118-120.

23. Burley SK, Berman HM, Christie C, Duarte JM, Feng Z, Westbrook J, et al. RCSB Protein Data Bank: Sustaining a living digital data resource that enables breakthroughs in scientific research and biomedical education. Protein science: a publication of the Protein Society. 2018; 27: 316-330.

24. Schrödinger LLC. The PyMOL molecular graphics system. Version 1.8. 2015.

25. Zainab B, Ayaz Z, Alwahibi MS, Khan S, Rizwana H, Soliman DW, et al In-silico elucidation of Moringa oleifera phytochemicals against diabetes mellitus. Saudi Journal of Biological Sciences. 2020; 27: 2299-2307.

26. Sameer S, Sudhakar M. Molecular Docking and ADME analysis for Anti-HIV1 potential of Quassinoids from Simarouba glauca. J of Pharmacol \& Clin Res. 2020; 8: 555742 .
27. Wang Y, Xiao J, Suzek TO, Zhang J, Wang J \& Bryant SH. PubChem: a public information system for analyzing bioactivities of small molecules. Nucleic acids research. 2009; 37: W623-W633.

28. Kumar RB \& Suresh MX. A computational perspective of molecular interactions through virtual screening, pharmacokinetic and dynamic prediction on ribosome toxin A chain and inhibitors of Ricinus communis. Pharmacognosy research. 2012; 4: 2.

29. Rathore PK, Arathy V, Attimarad VS, Kumar P \& Roy S. In-silico analysis of gymnemagenin from Gymnema sylvestre (Retz.) $\mathrm{R}$. Br. with targets related to diabetes. Journal of theoretical biology. 2016; 391: 95-101.

30. Singh Sudha, Noopur Khare and Abhimanyu Kumar Jha. "Structure Based Molecular Docking Analysis of Secondary Metabolites against DNMT1 to Treat Cervical Cancer". 2020.

31. Lipinski CA, Lombardo F, Dominy BW, Feeney PJ. Experimental and computational approaches to estimate solubility and permeability in drug discovery and development settings. Adv. Drug Deliv. Rev. 2001; 46: 3-26.

32. Daina A, Michielin O \& Zoete V. SwissADME: a free web tool to evaluate pharmacokinetics, drug-likeness and medicinal chemistry friendliness of small molecules. Scientific reports. 2017; 7: 1-13.

33. Daina A \& Zoete V. A boiled-egg to predict gastrointestinal absorption and brain penetration of small molecules. Chem Med Chem. 2016; 11: 1117.

34. Rani Nisha, Noopur Khare and Abhimanyu Kumar Jha. "Molecular Docking Study of Dihydrohelenalin against DNMT1 to Treat Oral Cancer". 2020.

35. Subramani SK, Gupta Y, Manish M \& Prasad GBKS. Gymnema Sylvestre A-Potential Inhibitor of COVID-19 Main Protease by MD Simulation Study. 2020.

36. Wadood A, Ahmed N, Shah L, Ahmad A, Hassan H \& Shams S. In-silico drug design: An approach, which revolutionarised the drug discovery process. OA Drug Des Deliv. 2013; 1: 3.

37. He J, Chen Y, Farzan M, Choe H, Ohagen A, Gartner S, et al. CCR3 and CCR5 are co-receptors for HIV-1 infection of microglia. Nature. 1997; 385: 645-649. 